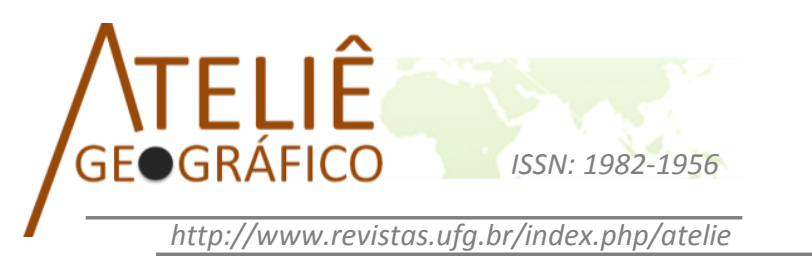

\title{
Paisagem antropogenética e a dinâmica do meio físico na porção sul da cidade de Belém-PA
}

\author{
Anthropogenic landscape and the dynamics of the physical \\ environment in the south part of Belém city, Pará-Brasil
}

\author{
Paisaje antropogénica y dinámica de los medios en \\ porción sur de la ciudad de Belém, Pará-Brasi
}

\author{
Antônio Carlos Ribeiro Araújo Júnior \\ Universidade Federal do Pará \\ aj_geo@hotmail.com
}

\begin{abstract}
Resumo
Falar em dinâmica do meio físico remete quase que instantaneamente a natureza (sentido amplo) em uma escala temporal de mudanças espacias geológicas. No entanto, a consideração da sociedade enquanto atuante na dinâmica natural de processos e formas sobre o relevo leva a considerá-la como importante agente geomorfológico capaz de intensificar ou atuar na gênese de formas e processos e nesse sentido busca-se discutir qual a relação entre a paisagem antropogenética e a dinâmica do meio físico tendo como exemplo a bacia hidrográfica da Estrada Nova (BHEN) na porção sul da cidade de Belém (PA), considerando que histórica e geograficamente intervenções humanas tornam locais processos naturais, potencializando áreas de risco a inundações e alagamentos. Para a discussão ora apresentada far-se-á uso de dados secundários sobre a população belenense, assim como revisão bibliográfica que relacione a ações humanas a dinâmica do meio físico.

Palavras-chave: Paisagem antropogenética, bacia hidrográfica da Estrada Nova, dinâmica do meio físico, risco.
\end{abstract}




\begin{abstract}
The approach on the dynamic of the physical environment promptly links 'nature' (in a broad sense) to a time scale of geological spatial changes. However, by taking into account the society as an acting geo-morphological agent in the natural dynamics of processes and types on the relief makes it as an important instrument able to intensify and act in the genesis of forms and processes; this way, the author seeks to debate the links between an anthropogenic landscape and the dynamics of the physical environment with a focus on the in the south part of Belem city, Para. Secondary data analysis on the Belem population and literature review on human actions on the physical environment dynamics are used as methodological procedures.
\end{abstract}

Keywords: Anthropogenic Landscape. Estrada Nova Hydrographic Basin (BHEN). Dynamics of Physical Environment. Risk.

\title{
Resumen
}

Hablar en dinámica del medio físico se refiere casi instantáneamente la naturaleza (sentido amplio) en una escala de tiempo geológico los cambios espaciales, es decir, miles de millones de años. Sin embargo, la consideración de la sociedad al actuar en la dinámica de los procesos naturales y las formas de relieve lleva a considerar como importante agente geomorfológico capaz de mejorar o actuar en la génesis de las formas y procesos y en consecuencia busca discutir la relación entre el paisaje antropogénica y la dinámica del medio físico teniendo como ejemplo la cuenca del Estrada Nova (BHEN) en la porción sur de la ciudad de Belém (PA), mientras que históricamente y geográficamente las intervenciones humanas hacen locales los procesos naturales de la ciudad de Belém, potenciando el aumento de las áreas de riesgo de inundación y anegamiento. Para la discusión presentada aquí hará que utilizará datos secundarios sobre belenense población, así como la revisión de la literatura que se refiere a las acciones humanas de la dinámica del entorno físico.

Palabras clave: paisaje antropogénica, cuenca del Estrada Nova, dinámica del medio físico, riesgo.

\section{Introdução}

Dentre as ciências sociais a Geografia apresenta uma particularidade que faz dela um excelente escopo para se empreender estudos sobre risco, falase da intrínseca relação sociedade-ambiente na qual a sociedade aparece como agressor e vítima (VEYRET, 2007) dos processos ocorrentes e desencadeados por conta de sua influência, sendo, portanto, agente ativo e passivo.

A porção sul da cidade de Belém desde a década de 1940 vem experimentando a ação antropogênica em razão da expansão urbana vivida pela cidade neste período, sendo que as áreas topograficamente mais favoráveis (que nesta época já eram escassas) já faziam parte da ocupação urbana. Procuraram-se então alternativas para um espraiamento "massivo" da população, a qual estava aumentando (resquícios do período da Borracha e da construção da estrada de ferro Belém-Bragança). 
Assim como a área central, através do secamento do alagado do Piry de Jussara durante o século XIX, a porção sul teve na construção do dique da Estrada Nova (atual Av. Bernardo Sayão) uma alternativa para uso do solo e ocupação urbana. Segundo dados do IBGE 1940 e 2010 a população residente no município de Belém passou de 206.866 para 1.393.399, um aumento de $673,58 \%$, sendo que $18,10 \%$ desta população residem na área da bacia hidrográfica da Estrada Nova satisfazendo uma média de 252.246 habitantes (gráfico 1).

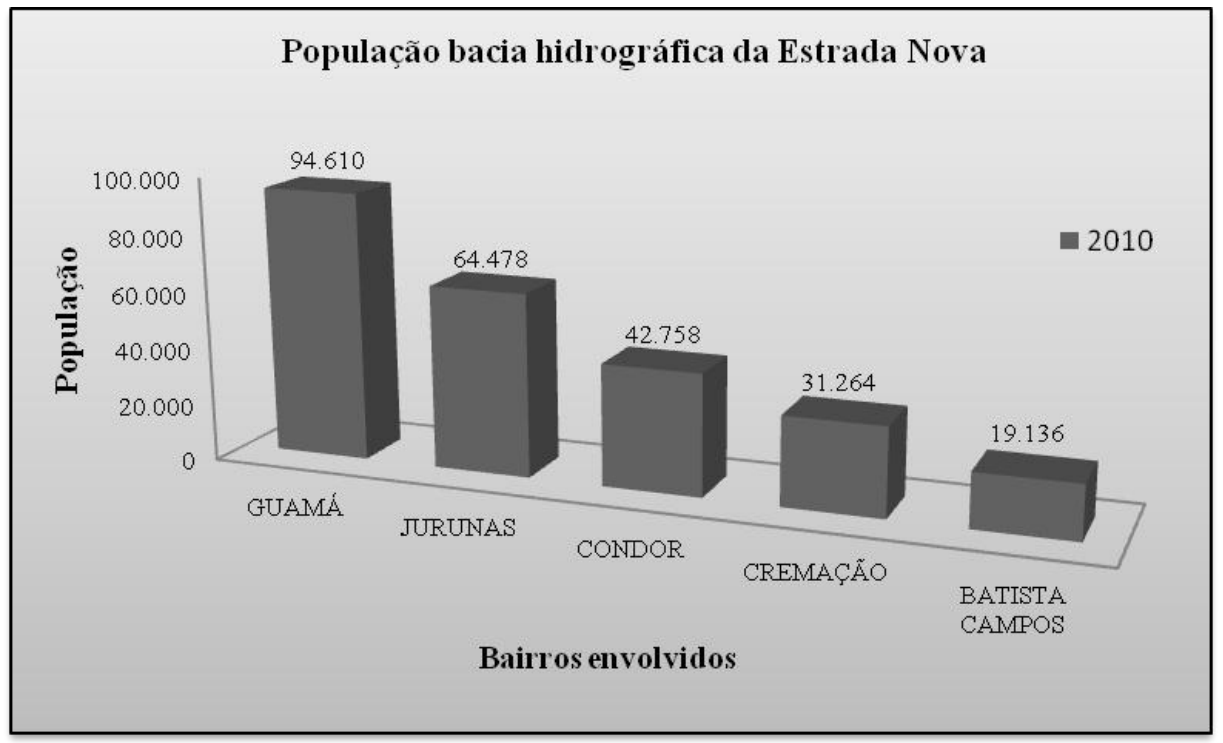

Gráfico 1: População residente na área da bacia hidrográfica da Estrada Nova. Fonte: IBGE, 2010

Os bairros do Guamá, Condor e Jurunas encontram-se espacialmente localizados as margens do rio Guamá na porção sul de Belém, já os bairros Cremação e Batista Campos, mesmo não estando em contato direto com o rio estão inseridos física e administrativamente na BHEN (figura 1). 


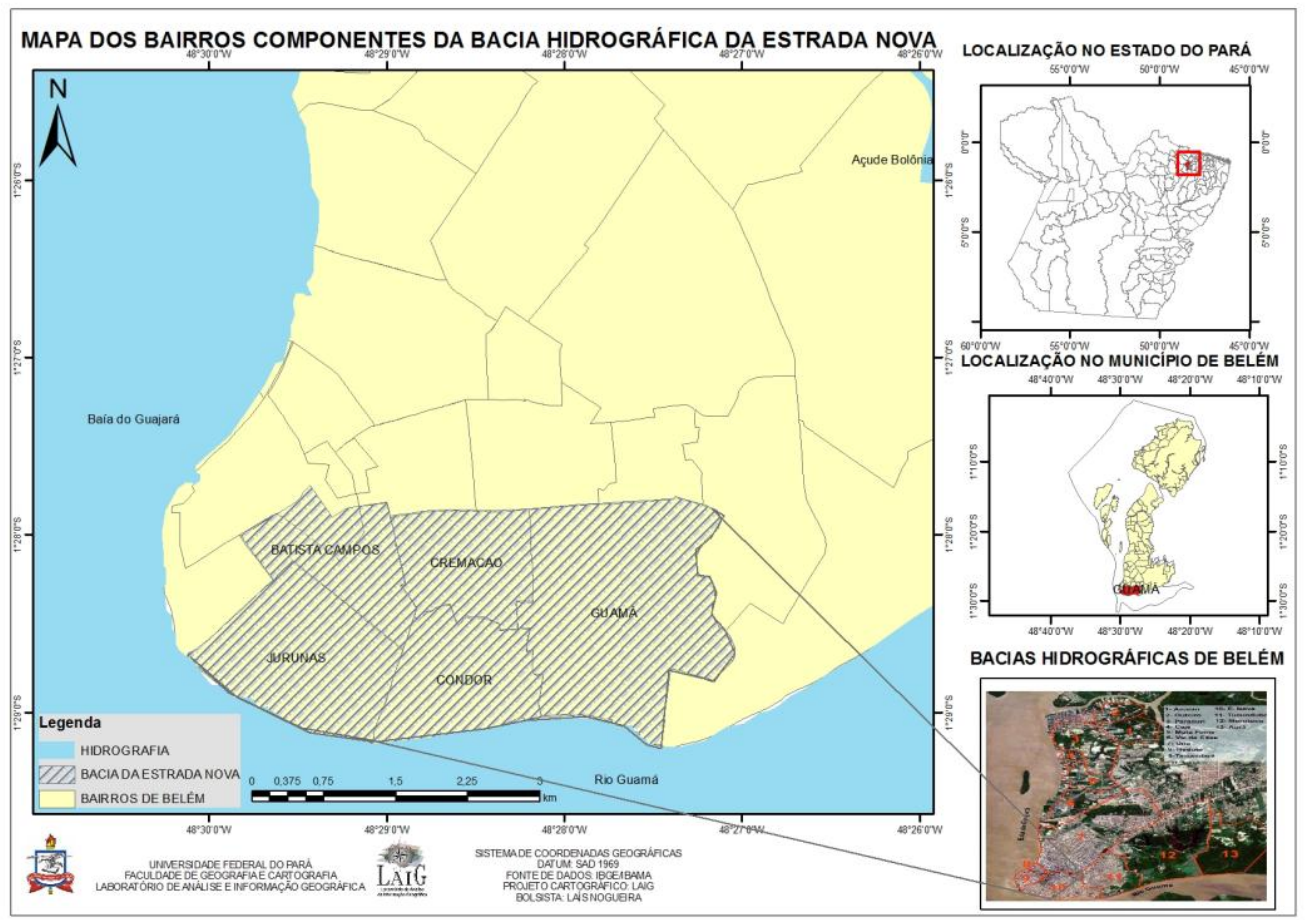

Figura 1 - Mapa dos bairros componentes da Bacia Hidrográfica da Estrada Nova

O aumento populacional faz com que os grupos sociais organizem o seu ambiente de variadas maneiras, transformando, intensificando ou mesmo criando formas e processos sobre o relevo, o qual pode ser entendido como síntese de formas e processos, que se pode apreender na paisagem por meio da observação.

Ao transformar, induzir, intensificar e criar formas e processos sobre o relevo, a sociedade acaba por desencadear fenômenos que em curto prazo, podem apresentar-se favoráveis e passíveis de controle sistemático. No entanto, muitas vezes o resultado destas ações é o desencadear de fenômenos que têm na sociedade seu principal vetor de impactação.

Diversos autores têm dedicado estudos à compreensão de como os grupos sociais provocam impactos sobre o meio físico, e por conta disso acabam sendo prejudicados pelas transformações ocorridas no ambiente (BRÜSEKE, 1997; HOGAN et al., 2000; DAGNINO e CARPI JR., 2007; VIEILLARD-BARON, 2007; CHRISTOFOLETTI, 2008). Tais autores 
sinalizam uma visão mais integrada a cerca da intensificação/geração de formas e processos, os quais modificam o meio bio-físico e colocam em risco o "bem estar" das sociedades.

De acordo com Veyret e Meschinet de Richemond (2007), há de se considerar que os territórios onde se verificam riscos, tanto naturais quanto tecnológicos ou sociais, são tributários de um passado nem sempre bem conhecido, e notadamente, de escolhas políticas ou econômicas cuja pertinência não pode ser compreendida senão no contexto de uma dada época.

Nesse sentido o trabalho tomará o uso do termo risco como uma categoria de análise que segundo Castro, Peixoto e Pires do Rio (2008) está associada à priori às noções de incerteza, exposição ao perigo, perda e prejuízos materiais, econômicos e humanos em função de processos de ordem "natural" (tais como os processos exógenos e endógenos da Terra) e/ou daqueles associados ao trabalho e às relações humanas.

O risco (lato sensu) refere-se, portanto, à probabilidade de ocorrência de processos no tempo e no espaço, não constantes e não-determinados, e à maneira como estes processos afetam (direta ou indiretamente) a vida humana.

Tanto os aspectos relacionados ao conceito de risco quanto dos agentes responsáveis pela alteração do modelado terrestre aqui abreviados serão melhor trabalhados a seguir com o intuito de discutir qual a relação entre a paisagem antropogenética e a dinâmica do meio físico tendo como exemplo a bacia hidrográfica da Estrada Nova (BHEN) na porção sul da cidade de Belém (PA).

Para a discussão ora apresentada far-se-á uso de dados secundários sobre a população belenense, assim como revisão bibliográfica que relacione a ações humanas a dinâmica do meio físico.

\section{Paisagem antropogenética}

As ações humanas sobre o meio físico têm sido intensificadas e seu poder transformador tem sido potencializado pelo avanço técnico e científico. As revoluções na agricultura, na indústria e na ciência deixaram registros na paisagem do período conhecido como Quaternário, indicando os modos pelos quais as sociedades apropriaram-se da natureza em diversos tempos e espaços.

Os processos de urbanização e industrialização têm tido um papel fundamental nos danos ambientais ocorridos nas cidades. O rápido crescimento causa uma pressão significativa sobre o meio físico urbano, tendo as consequências mais variadas, tais como: poluição atmosférica, do solo, das águas, deslizamentos, enchentes, etc (GUERRA e MARÇAL, 2006). 
Leva-se em consideração também que a ação antropogênica gera feições e formas de relevo locais, relacionadas à ação humana na história (até alguns poucos milhares de anos) e por intermédio do trabalho (entenda-se: interesses, atividades socioeconômicas e tecnologias disponíveis) (ARAÚJO Jr. e BARBOSA, 2010).

Para tanto planejar e gerir o espaço urbano se torna tarefa ímpar, posto a diversidade de relações que se estabelecem no meio intra-urbano, tornando-se necessário entender gestão como sendo não simplesmente gerenciamento ou administração (sem dúvida suportes imprescindíveis para sua prática), mas nos dizeres de Becker $(1987,1988)$ deve-se interpretar gestão como um saber específico, o de governação ou de governabilidade, que deriva basicamente de imperativos da empresa, implicando segundo Davidovich (1991) um sistema complexo de coordenação orientado para uma sociedade em rápida transformação.

Cada vez mais, torna-se necessário entender a sociedade como agente geomorfológico, que por meio do emprego de suas técnicas é capaz de transformar a paisagem em diferentes escalas. As ações sociais realizadas neste sentido podem ser denominadas de tecnogênicas, partindo desde a utilização dos primeiros instrumentos técnicos até a utilização de equipamentos capazes de modificar potencialmente as paisagens (LISBÔA, 2004).

Deveras insuficiente se faz apresentar e discutir a relação sociedadeambiente a luz do viés sistêmico aqui apresentado sem entender que no âmbito do planejamento urbano devem-se considerar os aspectos geomorfológicos, incluindo em sua análise uma abordagem histórica das formas de relevo, do material de cobertura superficial e dos processos geomorfológicos, pois revelam as dimensões das alterações ambientais no espaço urbano (FUJIMOTO, 2005).

Autores como Rodrigues (2005), que trabalha como o planejamento urbano pode acontecer tendo como metodologia a análise comparativa da morfologia original e morfologia antropogênica com exemplo da metrópole paulista a partir de escalas cartográficas distintas e Cunha $(2008,2009)$ que se dedica ao estudo dos canais fluviais e como a interferência da sociedade intensifica processos e gera formas, são exemplos da utilização do método sistêmico para fins de planejamento.

Diversas são as terminologias e os métodos empregados para explicitar os modos como a geomorfologia está sendo utilizada para entender as transformações empreendidas pelas sociedades que se apropriam do relevo, o qual é compreendido ao mesmo tempo como elemento da paisagem, recurso e risco (SUMMERFIELD, 1991; PANIZZA, 1996). Logo, a consideração do homem-sociedade no meio físico, como agente ativo dos processos de 
(antropo) morfogênese, é essencial para embasar estudos de caráter integrado que forneçam subsídios à gestão e ao manejo urbano-ambiental.

Guerra (2011) reuniu um conjunto de artigos pertinentes ao estudo do espaço urbano, em particular estudos que envolvem a geomorfologia urbana e como o entendimento das variáveis físicas no ambiente urbano podem fornecer subsídios ao decidir e como fazer para ocupar de forma racional o sítio urbano sem causar danos ao meio ambiente, as construções e aos habitantes das cidades.

À gênese de formas por parte da ação da sociedade chama-se antropogeomorfologia, a qual Rodrigues (2005) define como sendo o estudo do ambiente que resulta da presença e da intervenção antrópica no ambiente, é a relação no tempo e no espaço (NIR, 1983; GOUDIE, 1994), das mudanças no ambiente físico provocadas por ações antrópicas, considerando em sua análise três elementos morfológicos básicos: formas, materiais e processos da superfície terrestre (HART, 1986, apud, SANTOS FILHO, 2011).

Os estudos em antropogeomorfologia se desenvolvem a partir da emergência de se pensar o espaço, em especial o espaço urbano, concebendo-o como síntese máxima das alterações no meio físico para adaptabilidade e acomodação no intuito de atender uma das necessidades básicas do individuo que vive em sociedade, a moradia.

A questão da moradia, no entanto, perpassa por questões que vão além daqueles direitos assegurados pela constituição federal brasileira de 1988, entrando no debate sobre o que seria uma moradia socialmente justa. Harvey (1977) fala que o principio da justiça social se refere à divisão dos benefícios e alocação de encargos que surgem de um processo coletivo de trabalho. Este princípio também se refere aos ordenamentos sociais e institucionais associados com a atividade da produção e da distribuição.

Harvey (1977) continua dizendo que o princípio da justiça social também pode ser aplicado aos conflitos sobre centros de poder e de tomada de decisões, distribuição de influências, concessão de status social, instituições erigidas para regular e controlar atividades etc. No entanto os mecanismos utilizados para distribuição justa de recursos, renda etc, para indivíduos, grupos, organizações, territórios se fazem de forma (des) ordenada. Em uma palavra, o autor afirma que se trata de encontrar uma distribuição justa a quem pode obtê-la justamente.

O benefício da escolha (de melhores condições de vida) não se faz de forma justa, levando grandes camadas da sociedade a ultrapassar "fronteiras de risco" em ambientes urbanos (áreas de encosta, fundos de vale, planícies de inundação). Essa população não dispõe dos recursos financeiros e técnicos 
necessários para construção nessas áreas, tornando/transformando em curto prazo este recurso a vida (moradia), em um risco de morte (inundações, torrentes, deslizamentos de encostas etc).

Vitte, Cisotto e Vilela Filho (2010) e Vitte e Santos (2007) fazem apontamentos sobre o processo de expansão urbana e sua influência sobre as formas e processos do meio físico, gerando, intensificando e transformando o modelado terrestre potencializando o surgir de áreas de risco por tornar as populações, agora residentes em novas áreas, vulneráveis a processos "naturais".

Jorge (2011) fala que pela ausência quase que total de áreas urbanizadas destinadas à moradia popular levou a população de baixa renda a buscar alternativas à moradia, ocupando áreas vazias desprezadas pelo mercado imobiliário, nesse caso, áreas ambientalmente frágeis, como margens de rios, mangues e encostas íngremes. Cisotto e Vitte (2010) ainda falam que a natureza nas cidades deixa de ser uma necessidade social, perdendo seu significado real, transformando-se em objeto de consumo.

\section{Risco a inundação e Vulnerabilidade}

Risco, nada mais seria, segundo Veyret (2007) que a percepção de um perigo possível, mais ou menos previsível por um grupo social ou por um indivíduo que tenha sido exposto a ele, ou seja, tem-se o conhecimento dos acontecimentos que podem se produzir, assim como a probabilidade de ocorrerem.

Risco (risk) é utilizado pelos geógrafos como uma situação, que está no futuro e que traz a incerteza e a insegurança. Assim, há regiões de risco (regions of risk) ou regiões em risco (regions at risk) (MARANDOLA Jr e HOGAN, 2004). No entanto, isto não significa que estudar os riscos é uma tentativa de prever o futuro, mas aprender a planejar de forma compatível com as regiões de/em risco, de acordo com potencialidades de acontecimentos.

Nas ciências (naturais, sociais, etc) se tem a ideia de evolução permanente, que leva ao pensamento daquilo que poderá acontecer no futuro diante aquilo que é possível observar na atualidade. Por outro lado, segundo Rebelo (2010) existem as ocasionais manifestações dos fenômenos aos quais se imagina, o que permite testar previsões feitas e redesenhar hipóteses de trabalho.

Segundo Kobiyama et al. (2006) os estudos sobre impactos oriundos de desastres naturais ainda são insipientes no contexto brasileiro, contrastando com o cenário internacional. Na Amazônia pode-se destacar os trabalhos de 
Rodrigues (2008) no concernente a riscos provocados pela ação da sociedade, como também de Silva Jr (2010) em se tratando de risco à inundação na cidade de Alenquer.

Interessante é que a ideia de risco tem acompanhado a sociedade desde sempre. No princípio os riscos eram exclusivamente naturais, e além, aparecem outros como consequência das suas próprias atividades, tendo ou não a componente natural. Hoje, de acordo com Faugères (1991, apud REBELO, 2010) os riscos são de toda ordem, desde os naturais aos socioeconômicos ou aos tecnológicos e analisá-los em separado vem se tornando tarefa difícil, posto se constituírem em verdadeiros complexos de riscos (quadro 1).

Quadro 1: Discriminação de riscos associados a fatores endógenos e exógenos.

\begin{tabular}{|c|c|c|}
\hline Riscos & Fatores endógenos & Fatores exógenos \\
\hline Tectônicos & $\begin{array}{l}\text { Existem em praticamente toda a } \\
\text { Terra, mas são mais agudos perto } \\
\text { de limites ou bordas de placas. } \\
\text { Ligados a estes estão os riscos a } \\
\text { tsunamis. }\end{array}$ & \\
\hline Magmáticos & $\begin{array}{l}\text { São mais restritos em sua } \\
\text { distribuição, sendo considerados } \\
\text { ativos se funcionando nos últimos } \\
200 \text { anos (relacionam-se com } \\
\text { sismos). }\end{array}$ & \\
\hline Climáticos & & $\begin{array}{l}\text { A variação climática pode causar alta } \\
\text { pluviosidade (risco a inundação), como também } \\
\text { secas severas incorrendo em risco de } \\
\text { deflagração do fogo. }\end{array}$ \\
\hline Geomorfológicos & $\begin{array}{l}\text { Processos no interior da Terra } \\
\text { alteram as formas superficiais do } \\
\text { relevo (subsidência, subducção, } \\
\text { soerguimento) podendo levar a } \\
\text { riscos por desmoronamento. }\end{array}$ & $\begin{array}{l}\text { Processos erosivos em ligação com } \\
\text { características climáticas afetam a relativa } \\
\text { estabilidade do modelado através de fenômenos } \\
\text { episódicos e devastadores como ravinamento e } \\
\text { movimentos de massa (desabamento, } \\
\text { deslizamento e dependendo do gradiente } \\
\text { altimétrico avalanches). }\end{array}$ \\
\hline Hidrológicos & & $\begin{array}{l}\text { Riscos de inundação relacionam-se com os } \\
\text { riscos climáticos, mas implicam a consideração } \\
\text { de vários elementos naturais (dimensão e forma } \\
\text { da bacia hidrográfica, declives etc) e humanos } \\
\text { (barragens, diques, modo de ocupação do solo } \\
\text { etc). } \\
\text { Tais riscos relacionam-se também com riscos } \\
\text { de erosão fluvial ou marinha e com risco de } \\
\text { sedimentação. }\end{array}$ \\
\hline
\end{tabular}

Fonte: Elaborado a partir de Rebelo, 2003.

Os riscos discriminados no quadro 4 podem ser denominados de riscos naturais. Riscos naturais estão objetivamente relacionados a processos e 
eventos de origem natural ou induzida por atividades humanas (CASTRO, PEIXOTO e PIRES DO RIO, 2005), em consonância, a noção de perigo tecnológico (technological hazards), segundo Hewitt (1997), surge principalmente da tecnologia industrial, a partir de falhas internas, ao contrário dos perigos naturais (natural hazards), percebidos como uma ameaça externa.

De forma simplificada, pode-se considerar o risco vinculado a um acontecimento que pode realizar-se ou não. Contudo, a existência de um risco só se constitui quando há a valorização de algum bem, material ou imaterial, pois não há risco sem a noção de que se pode perder alguma coisa. Portanto, não se pode pensar em risco sem considerar alguém que corre risco, ou seja, a sociedade (CASTRO, PEIXOTO e PIRES DO RIO, 2005, p. 27).

Ao se considerar o risco como possibilidade de perdas lhe é atribuído um caráter espacial e os centros urbanos ganham especial atenção, por serem o lócus concentrador da população, o qual ainda estimula a produção industrial, as relações comerciais e prestação de serviços, ou seja, onde ocorre a produção e reprodução de processos produtivos e de um modo de vida.

O ambiente urbano guarda elementos potencias para se encontrarem áreas de risco a inundação, a deslizamentos, etc, bem como de perigos causadores de consequências desagradáveis, para tanto mensurar o grau de vulnerabilidade de uma área afetada por um determinado fenômeno é tarefa ímpar.

Diferenciar conceitos como os de risco, perigo e vulnerabilidade se faz importante e o quadro 2 pode se tornar bastante elucidativo neste sentido.

Quadro 2: Diferenciação conceitual para análise de risco.

\begin{tabular}{|c|l|}
\hline Termo & \multicolumn{1}{c|}{ Definição } \\
\hline Risco (risk) & $\begin{array}{l}\text { Risco é geralmente estimado pelo produto entre a probabilidade e as } \\
\text { consequências. }\end{array}$ \\
\hline Perigo (hazard) & $\begin{array}{l}\text { Uma condição com potencial de causar uma consequência } \\
\text { desagradável. Alternativamente, o perigo é a probabilidade de um } \\
\text { fenômeno particular ocorrer num dado período de tempo. }\end{array}$ \\
\hline Crise & $\begin{array}{l}\text { Realização concreta de um evento danoso cuja amplitude excede a } \\
\text { capacidade de gestão espontânea da sociedade que sofre este evento. }\end{array}$ \\
\hline $\begin{array}{c}\text { Elementos sob risco } \\
\text { (elements at risk) }\end{array}$ & $\begin{array}{l}\text { Significando a população, as edificações e as obras de engenharia, as } \\
\text { atividades econômicas, os serviços públicos e a infraestrutura na área } \\
\text { potencialmente afetada pelos processos considerados. }\end{array}$ \\
\hline $\begin{array}{c}\text { Vulnerabilidade } \\
\text { (vulnerability) }\end{array}$ & $\begin{array}{l}\text { Mede os impactos danosos do acontecimento sobre os alvos afetados. A } \\
\text { vulnerabilidade pode ser humana, socioeconômica e ambiental. }\end{array}$ \\
\hline $\begin{array}{c}\text { Análise de risco } \\
\text { (risk analysis) }\end{array}$ & $\begin{array}{l}\text { O uso da informação disponível para estimar o risco para indivíduos ou } \\
\text { populações, propriedades ou o ambiente. A análise de risco, geralmente, } \\
\text { contém as seguintes etapas: definição do escopo, identificação do } \\
\text { perigo e determinação do risco. }\end{array}$ \\
\hline
\end{tabular}

Fonte: Elaborado a partir de Castro, Peixoto e Pires do Rio (2005) e Veyret (2007). 
Empreendendo a análise sequencial risco-perigo-crise (figura 2) como sugerido por Rebelo (2003) percebe-se que o risco é a possibilidade de ocorrência ou não de um acontecimento - uma família ocupa uma área e pode ou não sofrer pelo fenômeno de subida da maré. Já o perigo é a exposição ao acontecimento - após a ocupação ocorreu uma inundação excepcional que pode trazer consequências terríveis a esta família e a crise seria a invasão das águas no imóvel com perdas materiais e humanas.

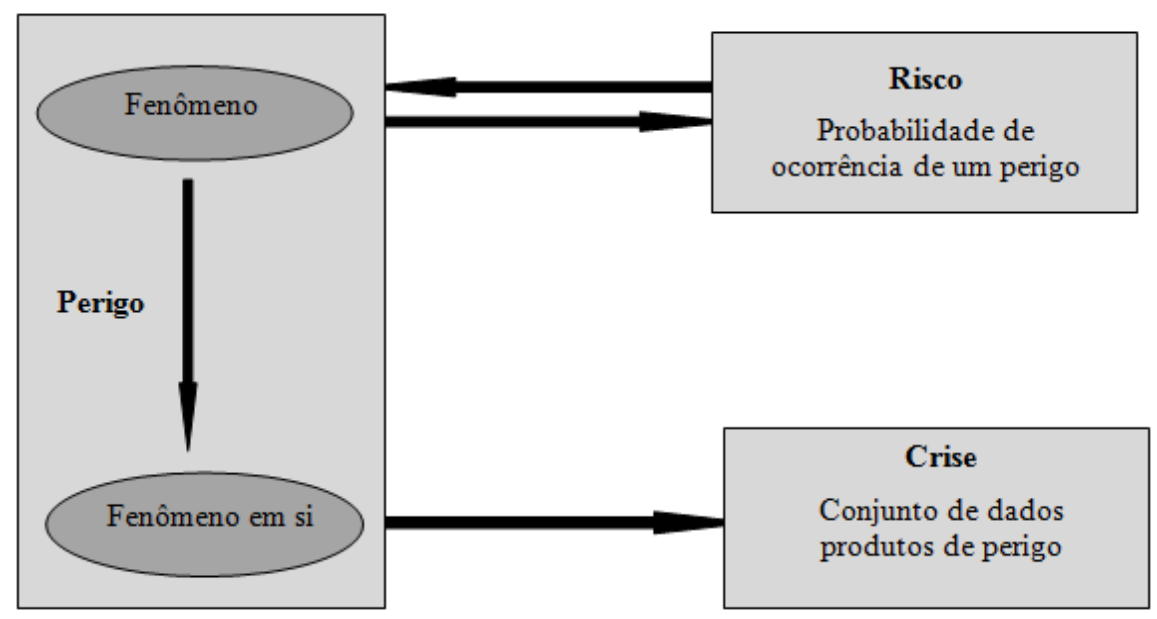

Figura 2: Esquema da relação entre os conceitos de Risco, perigo e crise. Fonte: adaptado de ANEAS DE CASTRO (2000).

Tal análise conduz a associar duas noções, a de risco e vulnerabilidade, as quais estão intrinsecamente ligadas (REBELO, 2003; VEYRET, 2007). A vulnerabilidade pode ser traduzida como a determinação de danos máximos em função de diversos usos do solo, colocando em jogo aspectos físicos, ambientais, técnicos, dados econômicos, psicológicos, sociais, políticos. Sendo insuficiente defini-la com simples índices científicos e/ou técnicos, uma vez que fatores socioeconômicos frequentemente aumentam a vulnerabilidade das populações ameaçadas.

Populações e estruturas vulneráveis potencializam a gênese de áreas de riscos. Em se tratando de inundações diversos são os exemplos de populações vulneráveis a eventos de precipitação extrema, com perdas de seus eletrodomésticos, imóveis e vidas humanas, ou mesmo tendo suas moradias categorizadas como localizadas em áreas de risco a inundação. 
Sabendo-se que Belém é uma cidade plana e com baixas cotas hipsométricas, esta apresenta trechos com grande risco de inundação, agravada pela forma (des) ordenada de ocupação da população, a qual visa suprir a necessidade básica da moradia com o mínimo de dignidade.

Coelho (2012) menciona que a incidência das inundações motivou as classes média e alta a se afastarem das áreas urbanas delimitadas como área risco. As inundações continuam a vitimar as classes baixa. Isto evidencia que as inundações não estão associadas somente com os aspectos do meio físico, mas também, com a questão socioeconômica da população (MONTEIRO, 1991, apud SANTOS, 2010).

Tucci (2000) vem reforçar que as inundações e os impactos em áreas urbanas podem ser produzidos por dois processos que ocorrem de forma isolada ou combinada que são: Inundações de áreas ribeirinhas e inundações devido a urbanização.

Relevante se faz colocar que as terminologias enchente, inundação e alagamento por vezes se confundem. Enchente é o escoamento superficial das águas decorrentes de chuvas fortes (COSTA, 2001).

Após suprir a retenção natural da cobertura vegetal, saturar os vazios do solo e preencher as depressões do terreno, as águas pluviais buscam os caminhos oferecidos pela drenagem natural e/ou artificial, fluindo até a capacidade máxima disponível, no sentido do corpo de água receptor final. Dependendo de uma série de fatores físicos e das proporções das chuvas, tais limites podem ser superados e os volumes excedentes invadem áreas marginais.

Estes volumes ao excederem a capacidade de retenção (transbordando) acabam por inundar o terreno (figura 3), ou seja, a inundação ocorre quando as águas dos rios, riachos, galerias pluviais saem do leito de escoamento devido a falta de capacidade de transporte de um destes sistemas e ocupa áreas onde a população utiliza para moradia, transporte (ruas, rodovias e passeios), recreação, comércio, industria, entre outros (TUCCI, 2003). 


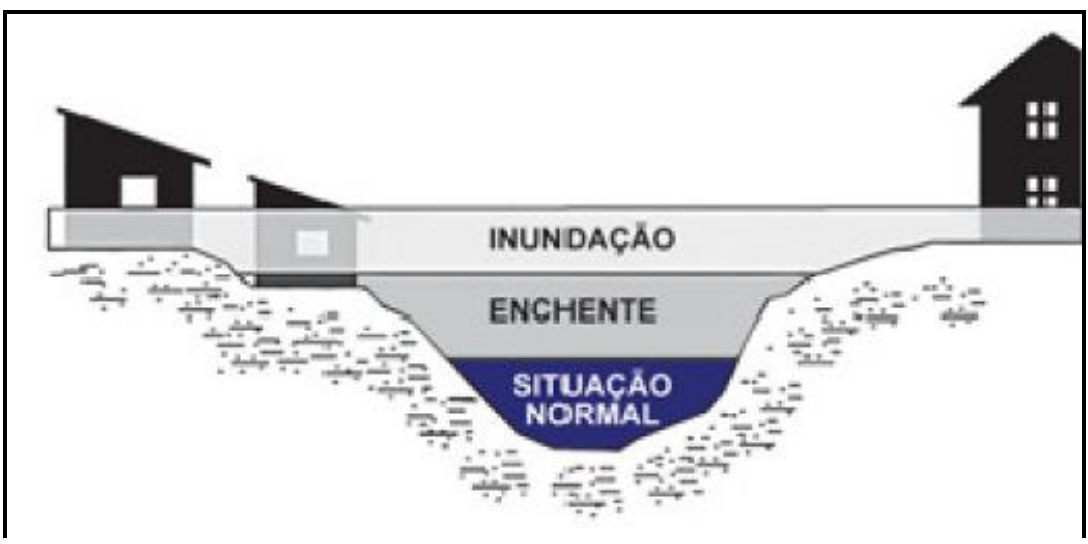

Figura 3: Perfil esquemático do processo de enchente e inundação.

Fonte: Brasil, 2007.

O alagamento seria então o processo decorrente ou não dos problemas de natureza fluvial, causando o acúmulo momentâneo de águas em um dado local por problemas de deficiência no sistema de drenagem devido a seu baixo coeficiente de escoamento superficial (SANTOS, 2010; SOUZA, 2004), no caso de Belém pela baixa hipsometria, incorrendo em efeitos estagnantes das águas.

SCHUELLER (1987, apud SANTOS, 2010) fala que geralmente os rios apresentam dois leitos um menor e outro maior (figura 4), o leito menor seria aquele pelo qual a água escoa a maior parte do tempo e o leito maior seria aquele invadido pelas águas com intervalos temporais mais extensos (um a dois anos).

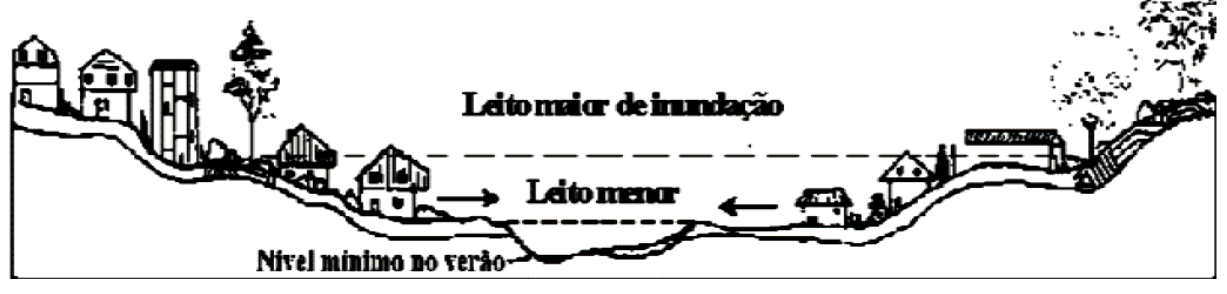

Figura 4: Características dos leitos do rio.

Fonte: SCHUELLER, 1987. 
Quando o escoamento transcende o leito menor ocorre a inundação natural do leito maior, querendo dizer com isso que o uso do solo e ocupação urbana processadas e em processo em áreas de leito maior estão sujeitas a inundação, podendo ser consideradas áreas de risco a inundação.

Tradicionalmente o gerenciamento de riscos associados a inundações é feito enfatizando-se a realização de medidas estruturais, tais como canalização e retificação dos corpos d'água. Perez Filho et al. (2006) falam que apesar dos altos custos financeiros e tempo envolvidos em ações como estas, via de regra, elas se mostram defasadas e insuficientes para solucionar os problemas relacionados e, não raro, provocam sua intensificação.

Medidas não-estruturais (em termos de engenharia) se fazem importantes considerar para minimização dos constantes riscos a inundação aos quais a população belenense está exposta, para tanto se faz importante entender qual o contexto político, econômico, social e ambiental o Programa de Recuperação Urbano e Ambiental na Bacia Hidrográfica da Estrada Nova (PROMABEN) está inserido.

\section{Mudanças antropogênicas em Belém (PA): o caso da BHEN}

O PROMABEN é um projeto da Prefeitura Municipal de Belém (PMB) com parte das obras de intervenção financiadas pelo Banco Interamericano de Desenvolvimento (BID) sendo iniciado em 2007 e com prazo de entrega para 2013, tendo como grande objetivo a promoção da melhoria da qualidade de vida da população do município de Belém - Pará através da valorização do meio ambiente urbano.

No entanto, na década de 1940, segundo IDESP (1990) e Trindade Jr. (1997), foram feitas intervenções, como a decorrente dos Acordos de Washington (de 17/07/1942) que viabilizaram transferências financeiras norteamericanas para a Amazônia, visando atingir setores de saneamento e saúde por meio do Programa de Proteção e assistência ao Trabalhador da Borracha.

O Seviço Especial de Saúde Pública (SESP), o Serviço Nacional de Malária (SNM) e o Departamento Nacional de Endemias Rurais (DNERu) iniciaram parte das obras indicadas pelo Departamento Nacional de Obras de Saneamento (DNOS), em 1941. Assim é que o dique foi construido em certa extensão e dotou de comportas automáticas as fozes dos principais igarapés. Mas por não possuirem engenharia adequada, duraram poucos anos (DNOS, 1963).

As obras empreendidas consistiam no preparo da orla (sul e oeste) de proteção da cidade, compreendida entre o igarapé do Tucunduba até o igarapé 
da Tamandaré, com 6,5 km de extensão aproximadamente (ALBUQUERQUE, 1993; RIBEIRO; 2004). As construções residenciais e comerciais eram proibidas na época, porém foram transgredidas, iniciando-se ainda na mesma ocasião a ocupação do solo por vários tipos de estabelecimentos comerciais (IDESP, 1990).

O crescimeto populacional de Belém foi novamente intensificado entre as décadas de 1940 e 1960 (gráfico 2), estando este processo ligado a implemetação dos Planos de Metas do Governo Federal e a construção da rodovia Belém-Brasília e neste período tem-se como reflexo o aumento do processo de ocupação das "baixadas", as quais segundo Trindade Jr (1997) são formas naturais integrantes do sítio de Belém que foram incorporadas ao tecido urbano a partir das necessidade requeridas no decorrer do processo de produção do espaço urbano belenense.

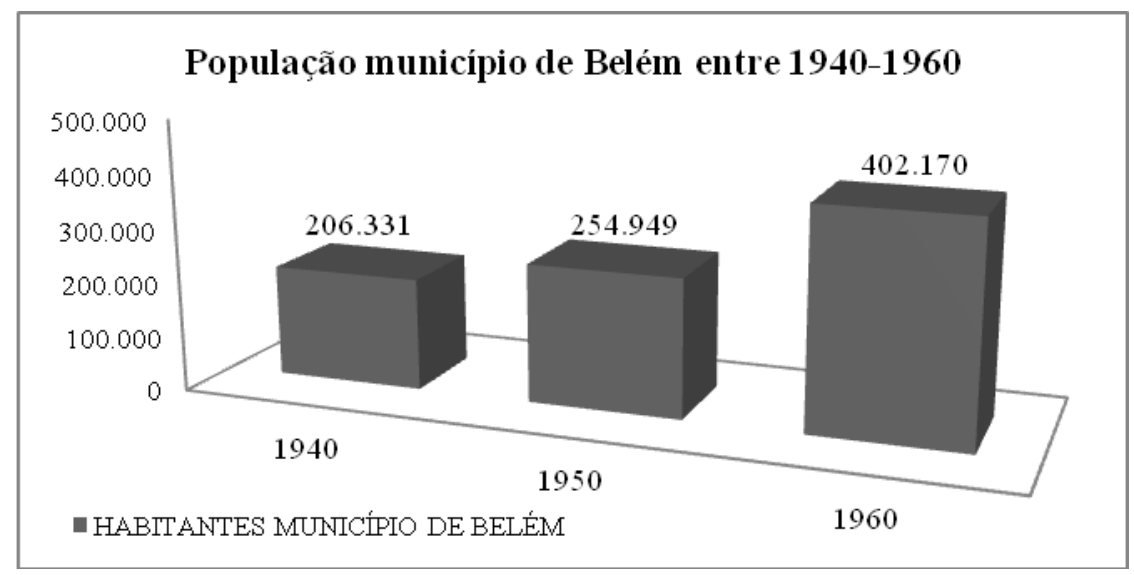

Gráfico 2: População município de belém entre 1940-1960. Fonte: Penteado (1968)

Belém experimentou um crecimento municipal da população em cerca de $194,9 \%$ quase dobrando sua população absoluta e os bairros situados as margens do rio Guamá e pertencentes a bacia hidrográfica da Estrada Nova passaram a ser reduto acolhedor da massa de pessoas que agora chegam a cidade. Tais áreas (baixadas) são desvalorizadas economicamente em razão do pouco ou nenhum (até então) oferecimento de equipamentos urbanos ${ }^{1}$, os quais tornam mais dignas as condições de moradia e valorizam o espaço.

\footnotetext{
${ }^{1}$ Equipamentos públicos de abastecimento de água, serviços de esgotos, coletas de águas pluviais, rede telefônica, etc. (LEI 6.766/79).
} 
Mesmo com condições de vida não tão satisfatórias na década de 1960 cerca de 59.044 pessoas ou $14,68 \%$ da população municipal de Belém se encontrava residente nos bairros pertencentes a referida bacia, em 2010 este efetivo alcançava 252.246 pessoas ou $18,1 \%$. Tais áreas eram e continuam sendo atrativas por sua proximadade ao centro da cidade, tendo como principal via de acesso a avenida Bernardo Sayão, bem como apresentam preços mais acessíveis para aluguel e compra de imóveis.

Um dos fatores que leva ao adensamento populacional nas áreas de baixada em Belém, principalmente aos bairros circunscritos a bacia hidrográfica da Estrada Nova é a grande intervenção de contenção das águas das marés nas décadas de 1940 e 1950. Com a implementação do Projeto Dique e Drenagem é construído um dique ao longo do rio Guamá que vai beneficiar uma extensa área. Os bairros de Batista Campos, Cremação, Condor, Jurunas e Guamá tiveram significativo crescimento populacional entre 1950 e 2010 por conta desta intervenção (gráfico 3).

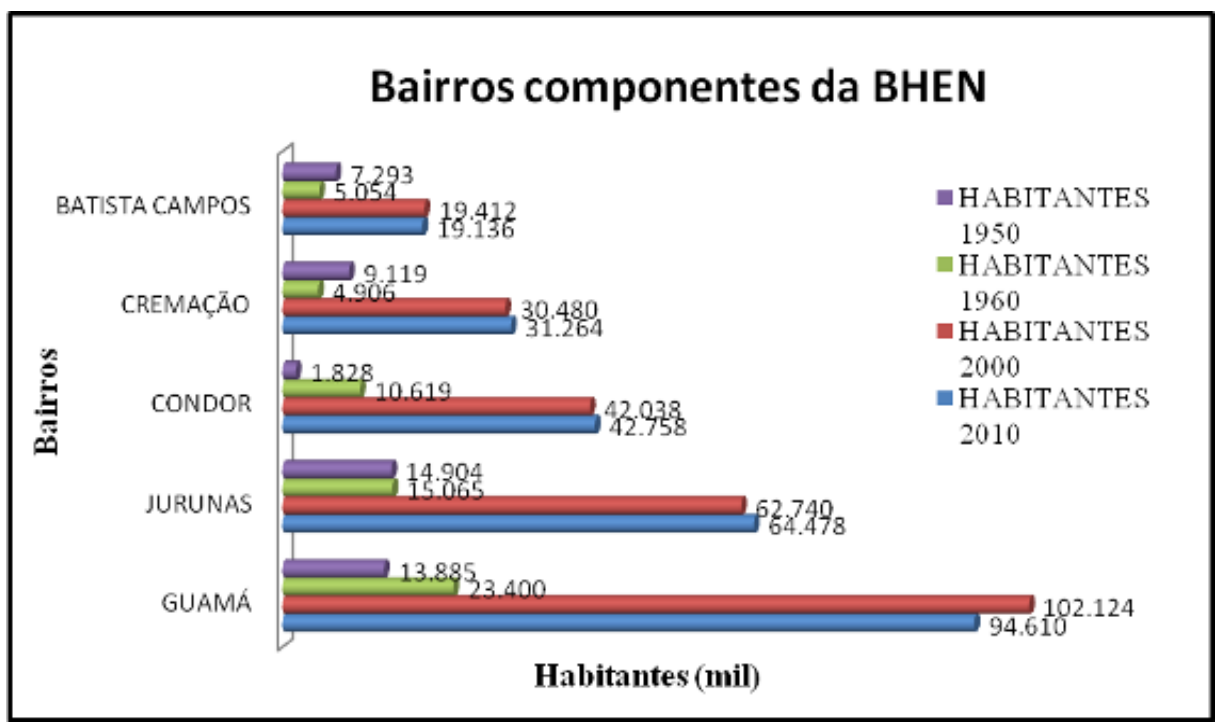

Gráfico 3: População dos bairros circunscritos a bacia hidrográfica da Estrada Nova antes e após a construção do dique (atual Av. Estrada Nova).

Fonte: elaborado pelo autor com base em Penteado (1968) e IBGE (2000, 2010). 
O saneamento processado na década de 1940-1950 foi sentido nas décadas de 1960 e posteriores, uma vez que não mais somente os bairros localizados as margens do rio passaram a ter crescimento populacional. Batista Campos e Cremação tiveram um crescimento populacional de 384,09\% e 621,28\%, respectivamente entre os anos 1960 e 2000.

Já os bairros situados as margens do rio Guamá tiveram extraordinários índices de crescimento populacional após as intervenções de drenagem e aterramento. O bairro da Condor registrou extraordinários 2.299,67\% de crescimento populacional entre 1950 e os anos 2000, Jurunas e Guamá expressimente aparecem com crescimeto de 420,96\% e 735,5\% respectivamente para o mesmo intervalo de tempo.

Após a implementação do projeto e construção do dique da Estrada Nova para conter as águas do rio Guamá, toda a área da bacia hidrográfica é beneficiada com redução significativa das áreas de inundação e alagamento, possibilitando a ocupação de forma menos insalubre da população que chega a Belém empurrada por projetos e programas do governo federal para desenvolvimento da região amazônica.

O projeto de saneamento de Belém tinha como objetivos: i) impedir que as áreas baixas da cidade fossem invadidas e inundadas pelas marés altas, quer pelo lado do rio Guamá, quer pelo da baía de Guajará, e, simultaneamente, ii) construir um sistema de drenagem destinado a recolher as águas das áreas já alagadas pelas inundações e chuvas (MENDONÇA, 2003).

Tais objetivos foram alcançados, sendo a eficiência do projeto questionada, uma vez que não somente tal intervenção seria suficiente para sanar o problema secular da ocupação das áreas de baixada de Belém, posto sua topografia (figura 5) assentar sobremaneira os problemas estagnantes $\mathrm{e}$ retentivos das águas fluviais adentrantes no espaço belenense via cursos d'água, os quais são intensificados pela pluviometria elevada em alguns períodos do ano. 


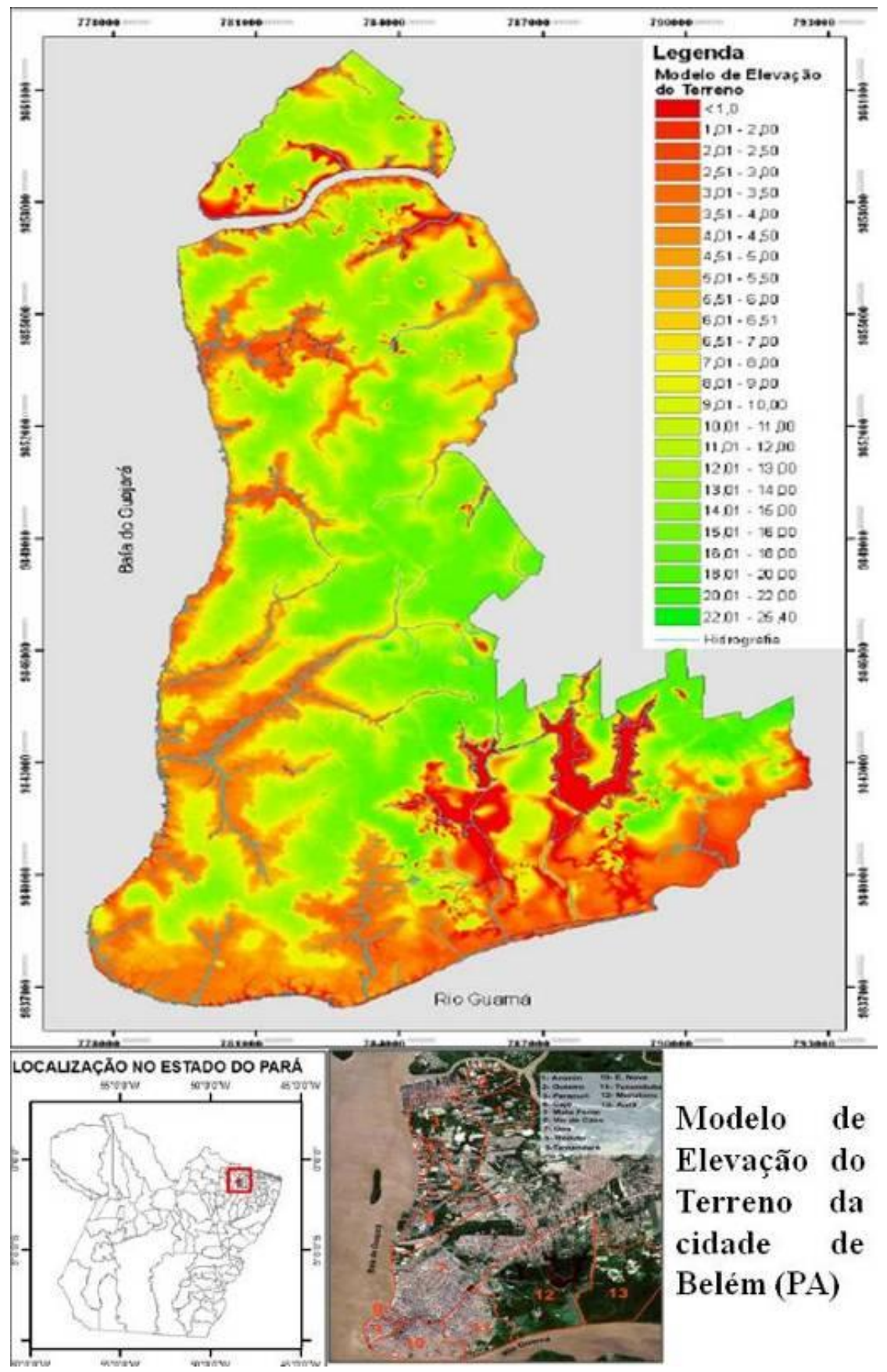

Figura 5 - Modelo de Elevação do Terreno da cidade de Belém (PA) Fonte: Adaptado de Santos (2010) 
Outras intervenções estão sendo processadas sobre a cidade de Belém, encontrando nos igarapés seus principais receptores. Os cursos d'água belenenses em razão da intervenção humana para adequação do espaço, visando seu uso e aproveitamento mais efetivo terão novas gêneses no concernente a suas formas, estas agora condicionadas a fatores antropogeomorfológicos.

Os estudos prévios para avaliar a implementação de obras na bacia hidrográfica da Estrada Nova por meio do Estudo de Impacto Ambiental (EIA) e do Relatório de Impacto Ambiental (RIMA) foram desenvolvidos pela empresa de consultoria mineira ENGESOLO Engenharia LTDA

O PROMABEN tem como princípios fundamentais (i) a busca de alternativas para promover o desenvolvimento sustentado através da reordenação urbana, tomando a referência da bacia hidrográfica como unidade de planejamento e (ii) busca de soluções integradas para os diversos subsistemas de infraestrutura e serviços urbanos intervenientes com a ocupação do solo (PMB, 2007a; 2007b).

No entanto, apesar do Programa ter como base, também, diretrizes ambientais sustentáveis (figura 6) o que esta se verificando em sua execução é a adoção de opções semelhantes às ocorridas no passado, com inúmeras canalizações, concretamentos, asfaltamentos e aterros dos canais, impermeabilizando cada vez mais os solos, o que le ao aumentando do escoamento superficial por diminuição da infiltração, o que potencializaria inundações e alagamentos.

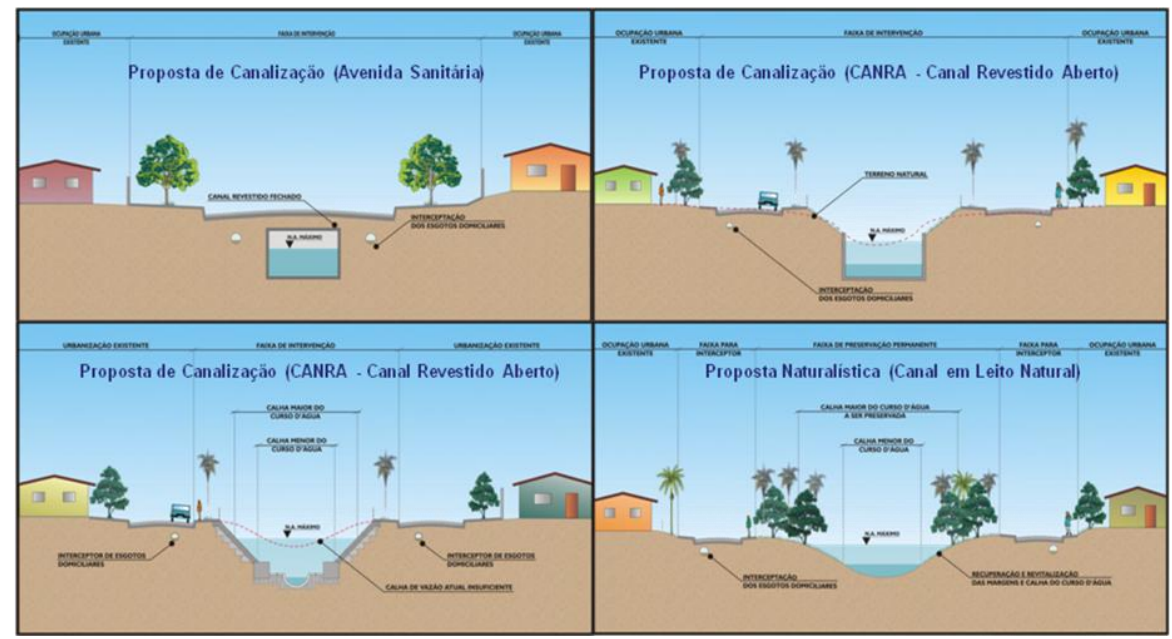

Figura 6: Propostas de intervenção nos canais componentes da BHEN.

Fonte: PMB (2007c). 
Dentre as quatro propostas apresentadas a Proposta Naturalística seria uma opção interessante para Belém e coadunaria com o proposto por Cunha (2009) no concernente a recuperação de canais fluviais, revegetando suas margens, restaurando as planícies de inundação, bem como os talvegues, além do que a interceptação dos esgotos domésticos seria feita por um sistema independente e isolado dos cursos d'água, minimizando os riscos de poluição hídrica.

Cabe destacar que o PROMABEN fazendo parte de um projeto maior o Portal da Amazônia, o qual consiste na abertura de uma "janela para o rio", no caso o rio Guamá, teve neste ano (2012) sua primeira fase inaugurada (figura 7), preliminarmente evidenciando que a proposta de canalização avenida sanitária esta sendo executada (figura 8).
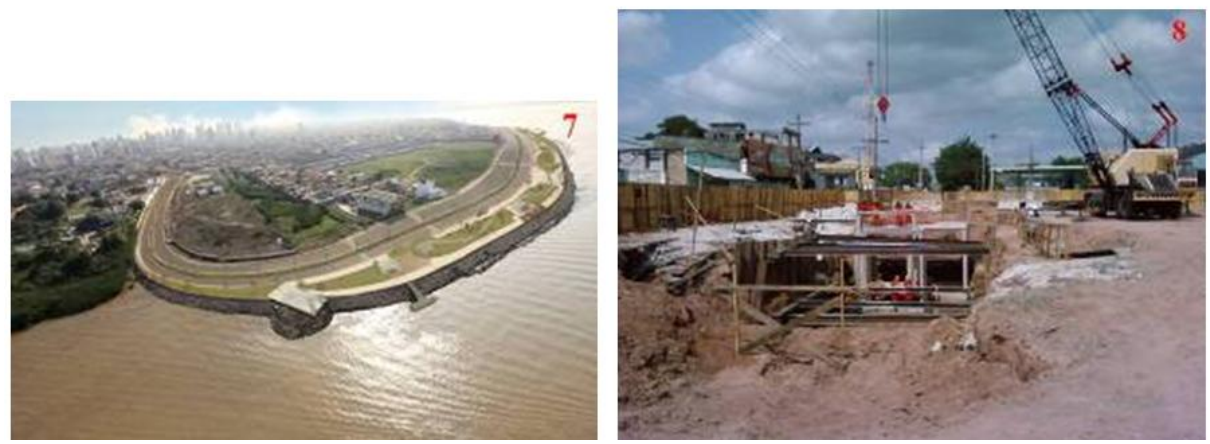

Figuras 7 e 8: Conclusão da primeira fase do "Portal da Amazônia" na figura 7, tendo como atributo ambiental evidente (quase único) o rio Guamá e na figura 8 tem-se a instalação das galerias pluviais após o completo aterramento do canal da Bernardo Sayão. Fonte: play47.blogspot.com e o autor.

A concretude e as possibilidades analíticas do conceito de bacia hidrográfica, considerando-a como unidade de planejamento e gestão, contribui sobremaneira ao ordenamento (NASCIMENTO, 2006) espacial, dá subsídios ao manejo ambiental, à luz dos recursos naturais e o desenvolvimento sustentável (NASCIMENTO e CARVALHO, 2003).

Tendo em vista o fato de que o Planejamento urbano-ambiental na bacia hidrográfica da Estrada Nova (BHEN) deverá estar voltado para a sua organização espacial, ou seja, o estabelecimento, segundo Rodríguez, Silva e Leal (2011), dos diferentes objetos em articulação com os sistemas espaciais e que a bacia hidrográfica constitui uma articulação sistêmica de objetos e 
formações espaciais, a BHEN foi delimitada para fins de planejamento urbano, não sendo desconsiderados aspectos geomorfológicos como a topografia.

\section{Considerações finais}

A intervenção humana no relevo confere a sociedade papel geomorfológico importante nas formas e processos naturais, por vezes modificando ou mesmo atuando na gênese de dinâmicas no meio físico. $\mathrm{Na}$ cidade de Belém (PA) verificam-se dinâmicas diversas principalmente nos cursos d'água, uma vez que a implementação de obras pontuais sobre o espaço deslocaram fenômenos, como as inundações e alagamentos para outros pontos da cidade.

Na década de 1940 a BHEN teve sua primeira intervenção humana processada, a qual sanou parcialmente o problema das inundações, as quais mais tarde foram transferidas para outros pontos, posto que a baixa topografia corrobora para fenômenos retentivos e estagnantes das águas das marés não somente no baixo curso dos canais fluviais.

Assim, considera-se que as mudanças antropogênicas processadas e em processo na porção sul da cidade de Belém deveriam considerar aspectos naturais com importância similar aos aspectos econômicos, políticos e sociais, uma vez que o entendimento integrado destas variáveis permite com que de fato planejar o espaço urbano ocorra de forma sustentável, deixando a população atingida pelo Programa ciente de todos estes aspectos.

A ciência da população sobre o início, meio e fim da obra é condição sine qua non para a posterior manutenção da obra e minimização de impactos negativos na BHEN, esclarecendo que esta é agente modificador potencial das dinâmicas naturais locais, em especial no seu espaço de convivência social.

\section{Referências}

AlbuQuerque, A. P. O dique de Belém. A Província do Pará, Belém, 20/dez. Segundo Caderno, 1993.

ANEAS DE CASTRO, S. D. "Riesgos y peligros: una visión desde lá Geografía". Scripta Nova: Revista Electrónica de Geografía y Ciencias Sociales. Barcelona, n.60, 15 de mar. 2000. 
ARAÚJO JR, A. C. R.; BARBOSA, E. J. S. A estrada e a paisagem: como a antropização atua sobre o relevo (um ensaio de Geomorfologia Ambiental). In: ENCONTRO NACIONAL DE GEÓGRAFOS, 16., Porto Alegre. Anais... Porto Alegre: AGB, 2010. 10 p.

BECKER, B. K. Geografia e Resgate da Geopolítica. Revista Brasileira de Geografia. Rio de Janeiro, IBGE v. 50, nº 2, p. 99-125, 1988.

. Elementos para a construção de um conceito sobre gestão do território. Seminário Laget. In: LAGET TEXTOS 1. Rio de Janeiro, CCMN/UFRJ, p. 1-4, 1987.

BRASIL. Mapeamento de riscos em encostas e margem de rios. CARVALHO, C. S.; MACEDO, E. S de.; OGURA, A. T. (orgs.) - Brasilia: Ministerio das Cidades; Instituto de Pesquisas Tecnologicas - IPT, 2007. 176 p.

BRÜSEKE, F. J. Risco social, risco ambiental, risco individual. Ambiente \& Sociedade. Campinas, v. 1, n. 1, p. 117-134, 1997.

CASTRO, C. M. de.; PEIXOTO, M. N. de O.; PIRES DO RIO, G. A. Riscos Ambientais e Geografia: Conceituações, Abordagens e Escalas. Anuário do Instituto de Geociências - UFRJ, v. 28, nº 2, p. 11-30, 2005.

CHRISTOFOLETTI, A. Aplicabilidade do conhecimento geomorfológico nos projetos de planejamento. In: GUERRA, A. J. T. \& CUNHA. S. B. da. (orgs.). Geomorfologia: uma atualização de bases e conceitos. $8^{\mathrm{a}}$ ed. - Rio de Janeiro: Bertrand Brasil, 2008, Cap. 11 , p. 415-440.

CISOTTO, M. F.; VITTE, A. C. O consumo da natureza no novo padrão de ocupação urbana. Revista Geografia em Atos. Departamento de Geografia da FCT/UNESP, Presidente Prudente, v.1, n. 10, p 26-39, 2010.

COELHO, M. C. N. Impactos ambientais em áreas urbanas - teorias, conceitos e métodos de pesquisa. In: GUERRA, A. J. T.; CUNHA, S. B. (orgs.). Impactos ambientais urbanos no Brasil, $9^{a}$ ed. Rio de Janeiro: Bertrand Brasil, 2012, Cap. 1, p. 19-45.

COSTA, H. Enchentes no Estado do Rio de Janeiro - Uma Abordagem Geral. Rio de Janeiro: SEMADS, 2001. 160 p.

CUNHA, S. B. da. Canais fluviais e a questão ambiental. In: CUNHA, S. B. da.; GUERRA, A. J. T. (orgs.). A questão ambiental: diferentes abordagens. $5^{\mathrm{a}}$ ed. Rio de Janeiro: Bertrand Brasil, 2009. Cap. 7, p. 219-238.

. Geomorfologia Fluvial. In: GUERRA, A. J. T. \& CUNHA. S. B. da. (orgs.). Geomorfologia: uma atualização de bases e conceitos. $8^{\mathrm{a}}$ ed. - Rio de Janeiro: Bertrand Brasil, 2008, Cap 5, p. 211-252. 
DAGNINO, R. de S.; CARPI JR., S. Risco ambiental: conceitos e aplicações. Climatologia e Estudos da Paisagem. Rio Claro, v. 2, n. 2, p. 50-87, 2007.

DAVIDOVICH, F. Gestão do Território, um tema em questão. Revista Brasileira de Geografia. Rio de Janeiro, IBGE, v. 53, n. 3, p. 77-31, 1991.

DEPARTAMENTO NACIONAL DE OBRAS E SANEAMENTO (DNOS). Estudos e projetos de saneamento para a cidade de Belém - Estado do Pará. Relatório preliminar, Rio de Janeiro, 1963.

FUJIMOTO, N. S. V. M. Considerações sobre o ambiente urbano: um estudo com ênfase na geomorfologia urbana. Revista do Departamento de Geografia, São Paulo, n. ${ }^{\circ} 16$, p. $76-80,2005$.

GOUDIE, A. S. The Human Impact in the Natural Environment. $4^{\mathrm{a}}$ ed. Cambridge (Massachusetts). The MIT Press, 1994. 376 p.

GUERRA, A. J. T. (org.). Geomorfologia Urbana. Rio de Janeiro: Bertrand Brasil, 2011. 280 p.

GUERRA. A.J. T.; MARÇAL, M dos S. Geomorfologia Ambiental. Rio de Janeiro: Bertrand Brasil, 2006. 190 p.

HARVEY, D. Urbanismo y Desigualdad social. Siglo veintiuno editores. Primera edición en español, febrero 1977. 340 p.

HEWITT, K. Regions of Risk. A Geografical Introduction to Disasters. Essex. Longman, 1997. 416 p.

HOGAN, D.; CUNHA, J.; CARMO, R.; OLIVEIRA, A. Urbanização e vulnerabilidades socioambientais diferenciadas: o caso de Campinas. In: ENCONTRO NACIONAL DE ESTUDOS POPULACIONAIS, 12. Caxambu. Anais... Caxambu: ABEP, 2000. 25 p.

IDESP, Belém: estudo ambiental do Estuário Guajarino. Belém: Idesp. Relatórios de Pesquisa $\mathrm{n}^{\circ} 17,1990.152 \mathrm{p}$.

INSTITUTO BRASILEIRO DE GEOGRAFIA E ESTATÍSTICA - IBGE. Censos demográficos 1950, 1980, 1991, 2000 e 2010. Disponíveis em: www.ibge.gov.br.

JORGE, M. do C. O. Geomorfologia urbana: conceitos, metodologias e teorias. In: GUERRA, A. J. T (org). Geomorfologia Urbana. Rio de Janeiro: Bertrand Brasil, 2011. Cap. 4, p. 117-146.

KOBIYAMA, M.; MENDONÇA, M.; MORENO, D.; MARCELINO, I.; MARCELINO, E.; GONÇALVES, E.; BRAZETTI, L.; GOERL, R. e MOLLERI, G. 
Introdução à prevenção de desastres naturais. Florianópolis: GEDN/UFSC, 2004. $109 \mathrm{p}$.

LISBÔA, T. H. C. Os depósitos tecnogênicos e a alteração da linha de costa do distrito sede de Florianópolis/sc. 2004, 96 f. Dissertação (Mestrado). Curso de mestrado em Geografia do Departamento de Geociências da Universidade Federal de Santa Catarina. UFSC/Florianópolis, 2004.

MARANDOLA Jr, E.; HOGAN, D. J. Natural hazards: o estudo geográfico dos riscos e perigos. Ambiente \& Sociedade - v. 7, nº. 2, p. 95-110, 2004.

MENDONÇA, C. L. Primeira macrodrenagem da cidade. O Liberal, Belém 24 de fevereiro, 2003.

NASCIMENTO, F. R. do. Degradação ambiental e desertificação no Nordeste brasileiro: o contexto da bacia hidrográfica do rio Acaraú - Ceará. 2006, 340 f. Tese (Doutorado). Programa de Pós-Graduação em Geografia da Universidade Federal Fluminense, uff/Rio de Janeiro, 2006.

NASCIMENTO, F. R do.; CARVALHO, O. Bacias hidrográficas como unidade de planejamento e gestão geoambiental: uma proposta metodológica. Revista Fluminense de Geografia. Niterói, n ${ }^{\circ}$, p. 61-82, 2003.

NIR, D. Man, a geomorphological agent: an introduction to anthropic geomorphology. Jerusalém, Ketem Pub. House, 1983. 165 p.

PANIZZA, M. Environmental Geomorphology. Amsterdan: Elsevier, 1996. 284 p.

PENTEADO, A. R. Belém: estudo de Geografia Urbana. Belém: Universidade Federal do Pará, vol. 2, 1968. 263 p.

PEREZ FILHO, A. et. al. Monitoramento e gerenciamento de bacias urbanas associados a inundação: diagnose da bacia do ribeirão quilombo na região metropolitana de campinas utilizando geotecnologias. Revista do Departamento de Geografia, $n^{\circ}$ 19, p. 44-54, 2006.

PREFEITURA MUNICPAL DE BELÉM - PMB, Programa de Recuperação Urbana e Ambiental da Bacia Estrada Nova. Relatório de Impacto Ambiental. Tomo 01/02: Engesolo Engenharia LTDA, 2007a. 315 p.

. Programa de Recuperação Urbana e Ambiental da Bacia Estrada Nova. Estudo de Impacto Ambiental. Tomo 02/03: Engesolo Engenharia LTDA, $2007 \mathrm{~b}$. $268 \mathrm{p}$. 
. Portal da Amazônia: urbanização da bacia da Estrada Nova e orla do rio Guamá. Secretaria Municipal de Urbanismo. Audiência UFPA. Apresentação de Slides, 2007c.

REBELO, F. Riscos naturais e ação antrópica: estudos e reflexões. Coimbra: Imprensa da Universidade, 2003. 286 p.

. Geografia física e riscos naturais. Coimbra: Imprensa da Universidade, 2010. $215 \mathrm{p}$.

RIBEIRO, K. T. S. Água e saúde humana em Belém. Belém: Cejup (Coleção Megam 2), 2004. $280 \mathrm{p}$.

RODRIGUES. J. Risco tecnológico: uma análise no porto de Vila do Conde. 2008, 95 f. Dissertação de Mestrado em Geografia. IFCH/UFPA, 2008.

RODRIGUES, C. Morfologia original e morfologia antropogênica na definição de unidades espaciais de planejamento urbano: exemplo na metrópole paulista. Revista do Departamento de Geografia, $n^{\circ}$ 17, p. 101-111, 2005.

SANTOS, F. A. A. dos. Alagamento e inundação urbana: modelo experimental de avaliação de risco. 2010, 165 f. Dissertação (Mestrado em Ciências Ambientais) Programa de Pós-Graduação em Ciências Ambientais, Instituto de Geociências, Universidade Federal do Pará, Museu Paraense Emilio Goeldi e EMBRAPA, Belém, 2010.

SANTOS FILHO, R. D. dos, Antropogeomorfologia Urbana. In: GUERRA, A. J. T (org). Geomorfologia Urbana. Rio de Janeiro: Bertrand Brasil, 2011. Cap. 7, p. 227246.

SILVA Jr, O. M. da Análise de risco a inundação na cidade de Alenquer - Estado do Pará. 2010, 103 f. Dissertação de Mestrado em Geografia. IFCH/UFPA, 2010.

SOUZA, C. R. G. Risco a inundação, enchentes e alagamentos em regiões costeiras. In: Simpósio Brasileiro de Desastres Naturais, 1, 2004, Florianópolis, Anais... Florianópolis : GEDN/UFSC, p. 231-247 (CD-ROM), 2004.

SUMMERFIELD, M. A. Global Geomorphology: an introduction to the study of landforms. Harlow - England: Pearson Prentice Hall, 1991. 537 p.

TRINDADE JR. S. C. C. da. Produção do espaço e uso do solo em Belém (PA). Belém: Universidade Federal do Pará/NAEA, 1997. 190 p.

TUCCI, C. E. M. Modelos hidrológicos. Porto Alegre: Ed. UFRGS, 2000. 680 p. 
Inundações e drenagem urbana. In: TUCCI, C.; BERTONI, C. E.M. Inundações urbanas na América do Sul. Associação Brasileira de Recursos Hídricos. Porto Alegre: ABRH, 2003. Cap. 3, p. 45-150.

VEYRET, Y. (Org.) Os riscos: o homem como agressor e vítima do meio ambiente. São Paulo: Contexto, 2007. 320 p.

VEYRET, Y.; MESCHINET DE RICHEMOND, N. O risco, os riscos. In: VEYRET, Y. (Org.) Os riscos: o homem como agressor e vítima do meio ambiente. São Paulo: Contexto, 2007, Cap. 1, p. 23-79

VIEILLARD-BARON, H. Os riscos sociais. In: VEYRET, Y. (Org.) Os riscos: o homem como agressor e vítima do meio ambiente. São Paulo: Contexto, 2007, Cap. 11, p. 275-316.

VITTE, A. C.; CISOTTO, M. F.; VILELA FILHO, L. R. A urbanização e a incorporação das várzeas ao espaço urbano de Campinas (SP), Brasil. Revista Geografar. Curitiba, v.5, n.1, p.105-132, 2010.

VITTE, A. C.; SANTOS, J. A. dos. A urbanização e as implicações socioambientais dos conjuntos habitacionais: o caso da cidade de Adamantina (SP). OLAM Ciência \& Tecnologia. Rio Claro/SP, Brasil Ano VII, v. 7, nº 2, p. 87-105, 2007.

\section{Antônio Carlos Ribeiro Araújo Júnior}

Geógrafo pela Universidade Federal do Pará.

Campus Setorial Básico - Instituto de Filosofia e Ciências Humanas.

Rua Augusto Corrêa, 01 - Guamá. CEP 66075-110. Belém-PA.

E-mail:aj_geo@hotmail.com

Recebido para publicação em outubro de 2012

Aprovado para publicação em junho de 2013 